Portland State University

PDXScholar

7-27-1977

\title{
Characterization of Trace Iron Species in Natural Water
}

James Robert Johnson

Portland State University

Follow this and additional works at: https://pdxscholar.library.pdx.edu/open_access_etds

Part of the Chemistry Commons

Let us know how access to this document benefits you.

Recommended Citation

Johnson, James Robert, "Characterization of Trace Iron Species in Natural Water" (1977). Dissertations and Theses. Paper 2387.

https://doi.org/10.15760/etd.2385

This Thesis is brought to you for free and open access. It has been accepted for inclusion in Dissertations and Theses by an authorized administrator of PDXScholar. Please contact us if we can make this document more accessible: pdxscholar@pdx.edu. 
AN ABSTRACT OF THE THESIS OF James Robert Johnson for the Master of Science in Chemistry presented July 27, 1977.

Title: Characterization of Trace Iron Species in Natural Water.

APPROVED BY MEMBERS OF THE THESIS COMMITTEE:

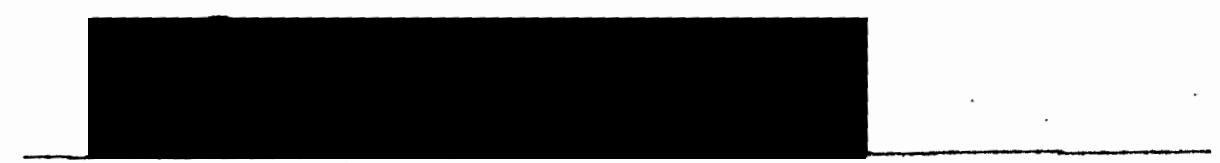
David K. Roe, Chairman

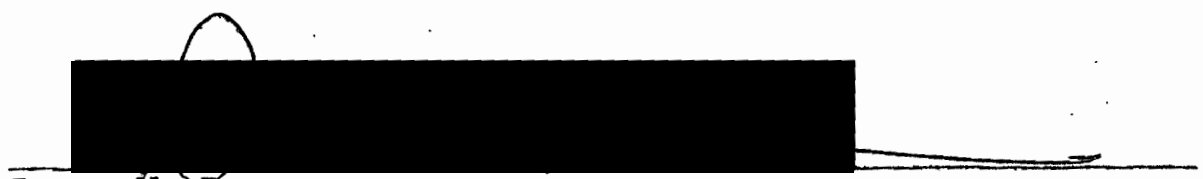
Bruce พ. Brown
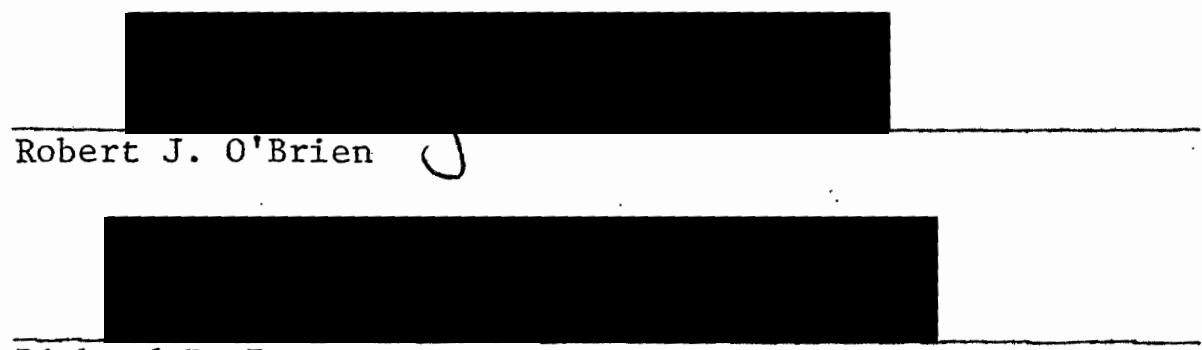

Richard R. Petersen

The distribution and speciation of trace metals in natural waters is only slightly, at best, understood. Interactions with organic substances can effectively distribute the metals throughout many ill-deined physical and chemical states. To better comprehend the complexity of $f$ metal-organic interactions this work focused on the delineation of trace iron species present in a natural system. The separation of. $\mathrm{Fe}$ (II) and Fe(III) was successfully accomplished using a variation of an ion exchange method involving resin-loaded filter paper. The quantitation of the various iron species was determined using linear scan voltammetry 
and atomic absorption. The total iron concentration, determined as the sum of the various separate species, compares favarably with the total iron concentration as determined directly using atomic absorption methods. 


\title{
CHARACTERIZATION OF TRACE IRON SPECIES
}

IN NATURAL WATER

\section{by}

JAMES ROBERT JOHNSON

\begin{abstract}
A thesis submitted in partial fulfillment of the requirements for the degree of
MASTER OF SCIENCE
in
CHEMISTRY
Portland State University 1977


TO THE OFFICE OF GRADUATE STUDIES AND RESEARCH:

The members of the Committee approve the thesis of

James Robert Johnson presented July 27, 1977.

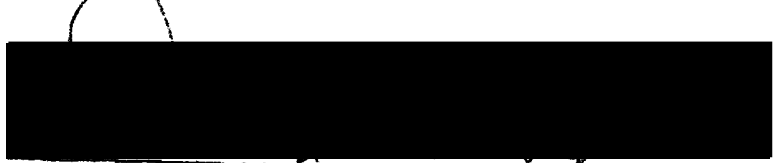

David K. Roe, Chairman
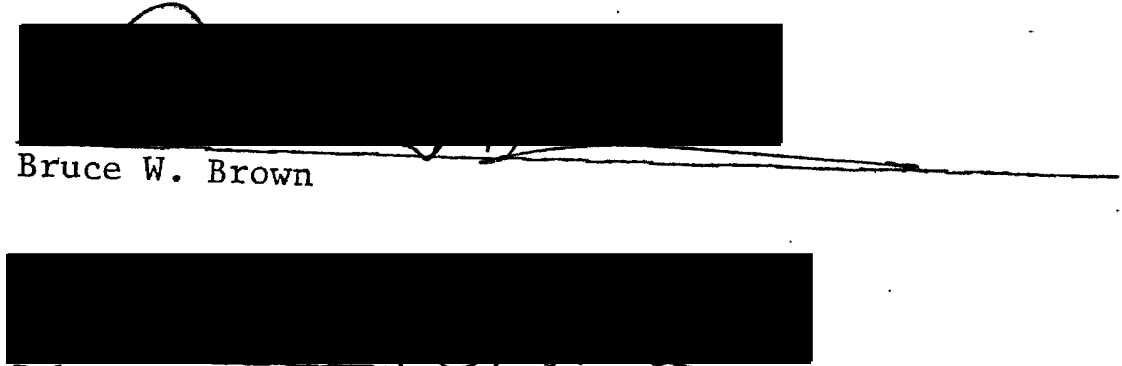

Robert J. O'Brieq]

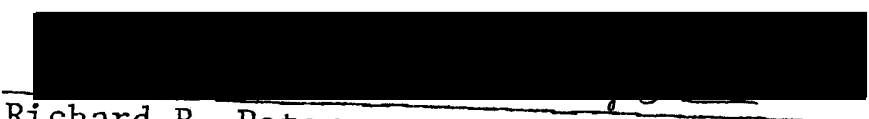

Richard R. Petersen

APPROVED:

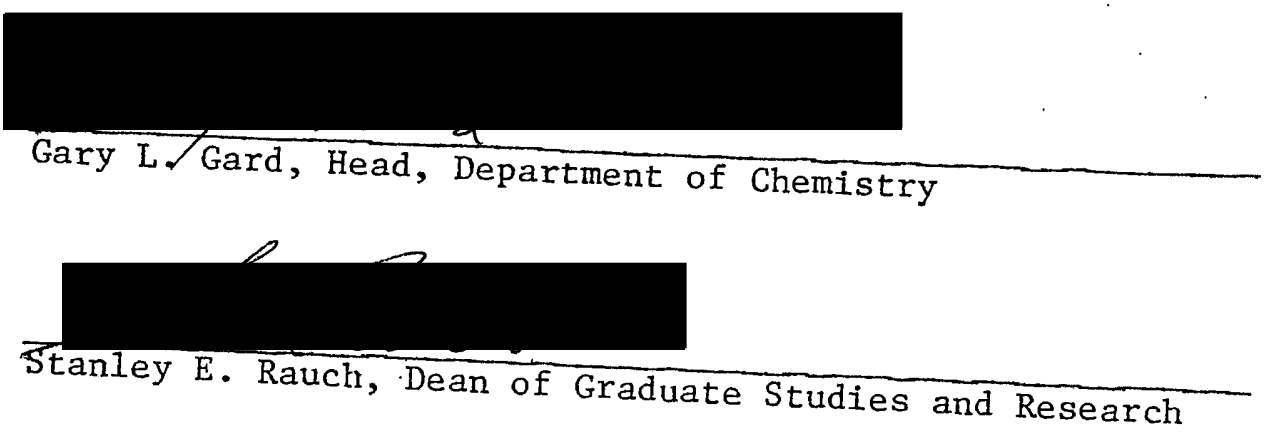




\section{ACKNOWLEDGEMENTS}

A special thanks is offered to Dr. David $\mathrm{K}$. Roe for his unfailing patience and to my wife, Laurie, for her encouragement and concern. 


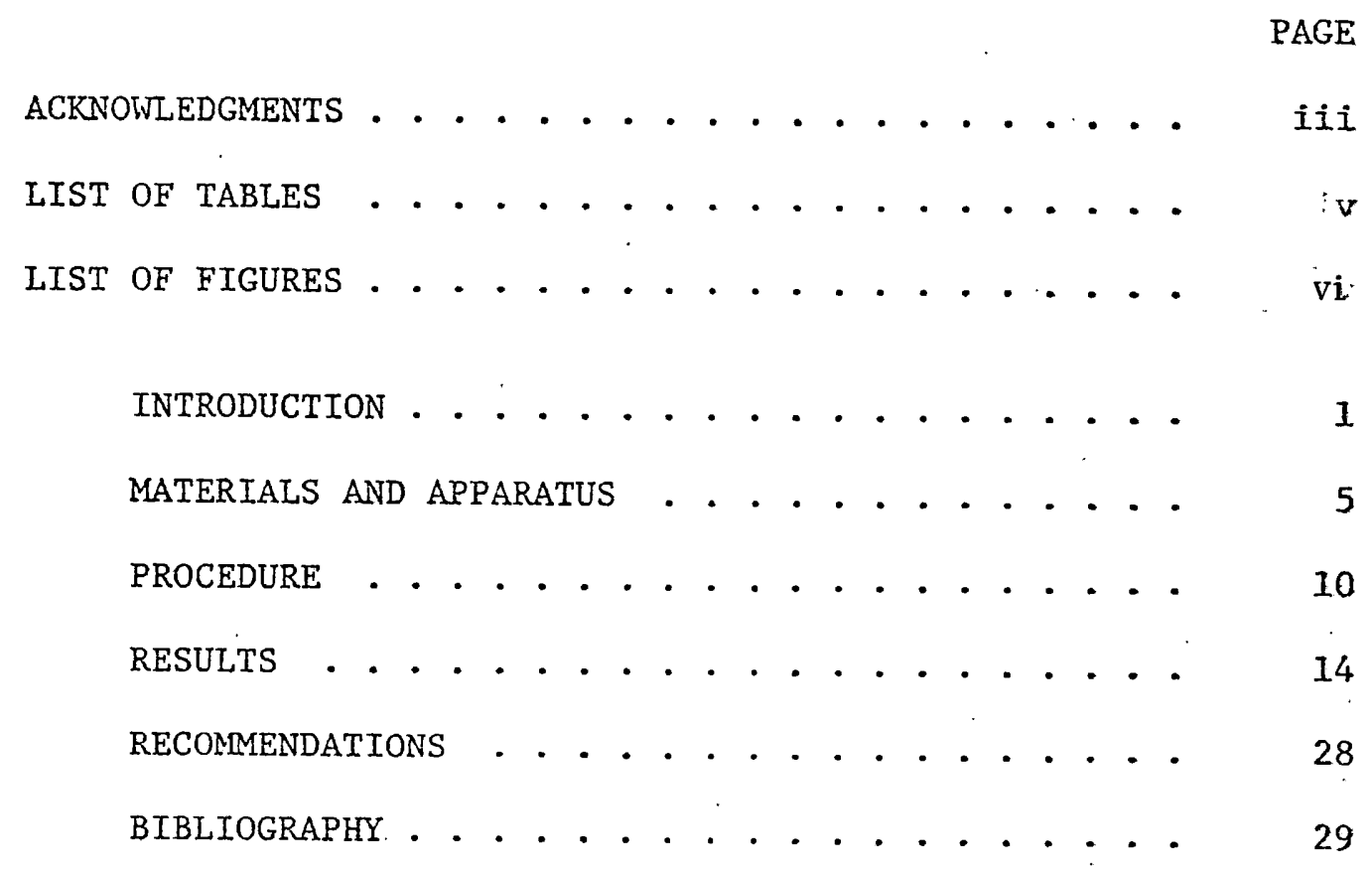




\section{LIST OF TABLES}

TABLE

PAGE

I Effect of $\mathrm{pH}$ on Extraction Efficiency . . . 14

II Optimum and Experimental Ion Exchange Parameters . . . . . . . . . 19

III Effect of Filtration Rate on Collection Efficiency .............. . 22

IV Average \% Iron Collected in Multiple Filtrations . . . . . . . . . . 23

V Fractional Analysis of Iron in Five River Water Samples . . . . . . . . . 26 
1 Cutaway Diagram of Electrochemical Cell .... 9

2 Cutaway Diagram of Filtering Apparatus . . . 11

3 Calculation of Optimum Flow Rate vs. Plate Height for $\mathrm{Fe}(I I)$. . . . . . . . 18

A Cyclic Scan Showing the Redox Current Curve for Fe-EDTA .. . . . . . . . 20

Simultaneous Analysis of $F e(I I)$ and $F e(I I I)$

Standard Mixtures . . . . . . . . 21

Loss of $\mathrm{Fe}(\mathrm{II})$ from Oxidation at $90^{\circ} \mathrm{C}$ and $\mathrm{pH}$

2.0 vs. Time... . . . . . 24 


\section{INTRODUCTION}

Most water quality standards specified today by our regulatory agencies require only that the total concentrations of trace metals be measured, and indeed, most environmental studies have based their recommendations and levied their penalties on just such inadequate information. It has become increasingly evident from recent studies (1) that the physiochemical form of the metal must be known to allow a meaningful interpretation of both its biological and geochemical reactions.

The concern about the importance of chemical speciation grew from the attempts to develop media for phytoplankton culturing (2). It soon became apparent that, regardless of the metal salts added, organisms would not grow well, if at all, unless some kind of chelating agent was introduced to the media either as a synthetic ingredient, by the organisms themselves (eg. ferrichromes) or by the addition of a small spike of a natural water. Thus, it was evidenced that metal interactions with physical systems were highly dependent on the chemical state.

For example, considering acute toxicity, arsenate ion will kill laboratory animals at a dose of $238 \mathrm{mg} / \mathrm{kg}$ of body weight, whereas arsenite is more than ten times more deadly, incurring lethal effects at $18 \mathrm{mg} / \mathrm{kg}$ (3). Tellurium, in the hexavalent state has been reported to exhibit positive carcinogenic effects. However, in the tetravalent state, there has been no cancer producing effects in like experiments (4). In addition to substantial variations due to oxidation state, there is also disagreement among studies involving identical systems. Schroeder and Mitchener 
(5) demonstrated marked carcinogenecity of the tetravalent oxyanion of selenium, $\mathrm{SeO}_{3}=$, but Shubik and Hartwell (6) show no such effects with the identical species in like experimental conditions.

Some work has also been done (7) to try to apply an equilibrium model to several bioassay test systems in order to define the chemical species of copper toxic to fish. When such elements are determined, the analysis is often performed by atomic absorption spectrophotometry, where all the metal is converted to the elemental form, or by colorimetric measurements, whereby all the chemical species (or often just the inorganic forms) are converted to the one form that will be suitable for the analysis. These methods, then, treat all the chemical species as if they are as toxic as the least desirable one.

In a recent publication in the New England Journal of Medicine, Dr. Thomas B. Eyl of St. Clair, Michigan summed up the current situation regarding environmental mercury contamination in his statement:

An even more serious source of almost certain error in our calculations to date is that most current tests measure only total mercury levels. Since fish usually contain 100 percent methyl-mercury, we have mistakenly jumped to several conclusions: that most or all of the total mercury found in food, blood, hair, etc. is organically bound (i.e. alkylmercury); that any other form of mercury in these samples is as dangerous as alkylmercury; and that the desirable level of mercury (alkyl- or total) for health and well being of plants, animals and man is nil (8).

The preceding discussion reflects the necessity of having a thorough understanding of the chemical makeup of the system in consideration. Since Dr. Eyl's statement, considerable work has been done to try to unravel this complex system of metal-organic interactions $(9,10)$. Surprisingly little work has been completed concerning the distribution and speciation of iron in natural waters. This is probably due to three major factors: although iron is one of the most abundant trace species 
it is one of the least exotic as far as environmental pollutants are concerned; there is a general lack of quick, reliable methods sensitive enough to determine both ionic species; and there are the procedural problems in working with ferrous ion solutions as they are easily oxidized by atmospheric oxygen.

Four major assumptions may be made concerning iron in a natural water system:

1. Only a small percentage of the total iron $(<15 \%)$ is transported in some kind of organic phase (11).

2. The iron that is organically bound is bound fairly strongly. Fe(II) conditional stability constants were measured for fulvic acid and were found to be $\log \mathrm{K} 5.1$ and $\log 5.8$ at $\mathrm{pH} 3.5$ and pH 5.0 respectfully (12).

3. Iron is likely to be reduced to the ferrous state when binding to organic acids and tends to be stabilized in that state (13).

4. It may be inferred from Rashid's work (14) that $\mathrm{Fe}$ (II) is bound to humic acid in concentrations three to four times higher than $\mathrm{Fe}$ (III). He did not actually use the $\mathrm{Fe}$ (II) - Fe(III) system, but found for other metals that divalent forms are bound three to four times the concentration of trivalent metals.

Iron, itself is not particularly toxic or mutagenic, although the

ferrous form seems to be somewhat more harmful in biological systems (15). The U. S. Public Health Service recommends that the concentration of iron not exceed $0.3 \mathrm{mg} / 1$ in drinking water; the limit not based on toxicity, but on esthetic and taste considerations (16). However, iron is a major micronutrient in natural systems and its biological uptake can be shown to depend on whether or not the ion is complexed (17). Also, 
the solubilization and complexing of iron by organic matter may have a role in preventing the transport of much more toxic species by occupying the majority of the complexing sites available.

Clearly, then, the chemical availability of iron as any given species would be expected to depend on three factors:

1. That fraction of the metal found in the inorganic form (as chlorides, carbonates, hydroxy complexes, etc.) as opposed to that found in conjunction with various organic ligands.

2. That amount which is adsorbed on soils or other solid surfaces.

3. That amount which exists as a colloid, floc or a definite precipitate.

The major question still left unanswered by these research efforts is the determination of the amounts of the various valence states associated with each of the three above conditions. It was the focus of this research to attempt to resolve this problem using the combined methods of ion-exchange and linear scan voltammetry. A laboratory method was developed and then adapted to a natural water sample in an effort to determine the distribution of iron species in that system. 
EDTA :

Analytical reagent grade ethylenediaminetetraacetic acid-disodium sait was obtained from Mallinckrodt Chemical Works (St. Louis, Missouri) and was found to be sufficiently free of iron for use in this study.

Ferric and Ferrous Ammonium Sulfates:

These salts were also of reagent grade obtained from Mallinckrodt. Both metal salts were dissolved in distilled water previously adjusted to $\mathrm{pH} 2$ with $\mathrm{HCl}$ to prevent hydrolysis. In addition, the ferrous iron was deoxygenated by bubbling a stream of nitrogen through the solution for forty-five minutes. The $\mathrm{N}_{2}$ was previously purified of traces of oxygen by passing the nitrogen through a scrubber of basic catechol. This solution was shielded from light to prevent photooxidation of the iron. The ferrous iron was discarded when a drop placed in a saturated solution of anthranilic acid at $\mathrm{pH} 4.5$ gave a precipitate indicating ferric iron was present (18).

Malonic Acid:

Malonic acid was obtained from Matheson Company, Inc. (Norwood, Ohio). A 0.IM solution was made to be used in conjunction with EDTA as a complexing agent.

\section{Sodium Acetate:}

Reagent grade sodium acetate was obtained from Mallinckrodt and was used without further purification. 
Glacial Acetic Acid:

Reagent grade acetic acid was obtained from Allied Chemical, Morristown, New Jersey and was used without further purification. This was combined with sodium acetate to make buffer solutions of $\mathrm{pH} 4.5$ and pH 5.5 .

Hydrochloric Acid:

Reagent grade hydrochloric acid was obtained from Du Pont and Co., Wilmington, Delaware and was used without further purification. AII glassware and polyethylene containers were rinsed with a 1:5 hydrochloric acid:distilled water solution prior to use.

Nitric Acid:

Reagent grade nitric acid was obtained from Mallinckrodt and was used without further purification.

\section{Sulfuric Acid:}

Reagent grade sulfuric acid was obtained from Allied Chemical and was used without further purification.

\section{Perchloric Acid:}

Reagent grade perchloric acid was obtained from Mallinckrodt and was used without further purification.

\section{Anhydrous Sodium Carbonate:}

Anhydrous sodium carbonate was obtained from Mallinckrodt and was analyzed for iron content by atomic absorption and found to contain less than $1 \mu \mathrm{g} / \mathrm{gm}$. This was deemed high enough to require a blank to be determined along with the sample. 
Hydrofluoric Acid:

Reagent grade hydrofluoric acid was obtained from J. T. Baker Chemical Co., Phillipsburg, New Jersey and it was determined to contain approximately ten micrograms of iron per milliliter which meant that a blank must. Ee analyzed along with each sample.

Sodium Chloride:

Reagent grade sodium chloride was obtained from J.T. Baker Co. and was used without further purification. A $0.1 \mathrm{M}$ solution was made to be used as the reference cell solution.

Ion-Exchange Resin Loaded Papers:

The SA-2 (strong acid) paper is constructed of $\alpha$-cellulose fiber matrix into which are imbedded tiny ( 240 micron) resin beads of Amberlite IR-120 cation-exchanger. It has a functional pH range from $1-14$ and the manufacturers stated capacity is 1.8 to 2.0 milliequivalents per gram of resin. The one centimeter discs, of approximately $0.4 \mathrm{~mm}$ thickness, weighed $12.7 \pm 0.5 \mathrm{mg}$. Based on an average weight of $13 \mathrm{mg}$ (or $6.5 \mathrm{mg}$ resin) the exchange capacity was about .012 meq. The usable exchange capacity, however, was about $.010 \mathrm{meq}$ as the outside of the rim of the disc was used for holding it in place and not available for ion exchange. The commercially available resin loaded papers were obtained from $\mathrm{H}$. Reeve - Angel and Company, Clifton, New Jersey and were used without further purification after rinsings with cyanide and EDTA failed to reveal any iron contamination detectable by atomic absorption. (Less than 0.01 micrograms per resin disc). 
Electrodes and Cell Design:

An electrochemical cell was designed and fabricated from lucite polymer as shown in the assembly diagram in Figure 1. The reference electrode compartment was filled with $0.10 \mathrm{M} \mathrm{NaCl}$ wnd sealed with a porous Vycor plug to act as a salt bridge. Connection to the potentiostat was made by inserting a silver chloride coated silver strip into the salt solution. The counter electrode consisted of a piece of tantaIum foil epoxied to the lucite plug and connected by a copper wire attached to the foil with a silver-filled, electrical conducting epoxy. The indicator, or working, electrode was fabricated from a small piece of platinum foil affixed in the same manner as the tantalum foil. The cell was constructed with ports for flushing an inert gas through the cell to eliminate oxygen, but for this study the potentials were in a range such that the reduction of oxygen electrochemically was not a major problem.

\section{Electronic Apparatus:}

The electrochemical measurements were performed by linear sweep voltammetry (LSV) of a method described previously (19). Basically, it involves the scanning of a potential at a rate typically ranging from 10 to $500 \mathrm{mv} / \mathrm{sec}$ between two stationary electrodes in an unstirred solution. This short sweep time gives much higher sensitivities than conventional d.c. polargraphy. Although the sloping baseline may still be a minor problem, it can be eliminated with a differentiator. The sensitivity of this method approaches $10^{-6}$ to $10^{-7} \mathrm{M}$. A Hewlett-Packard 7040-A X-Y recorder was also utilized. 


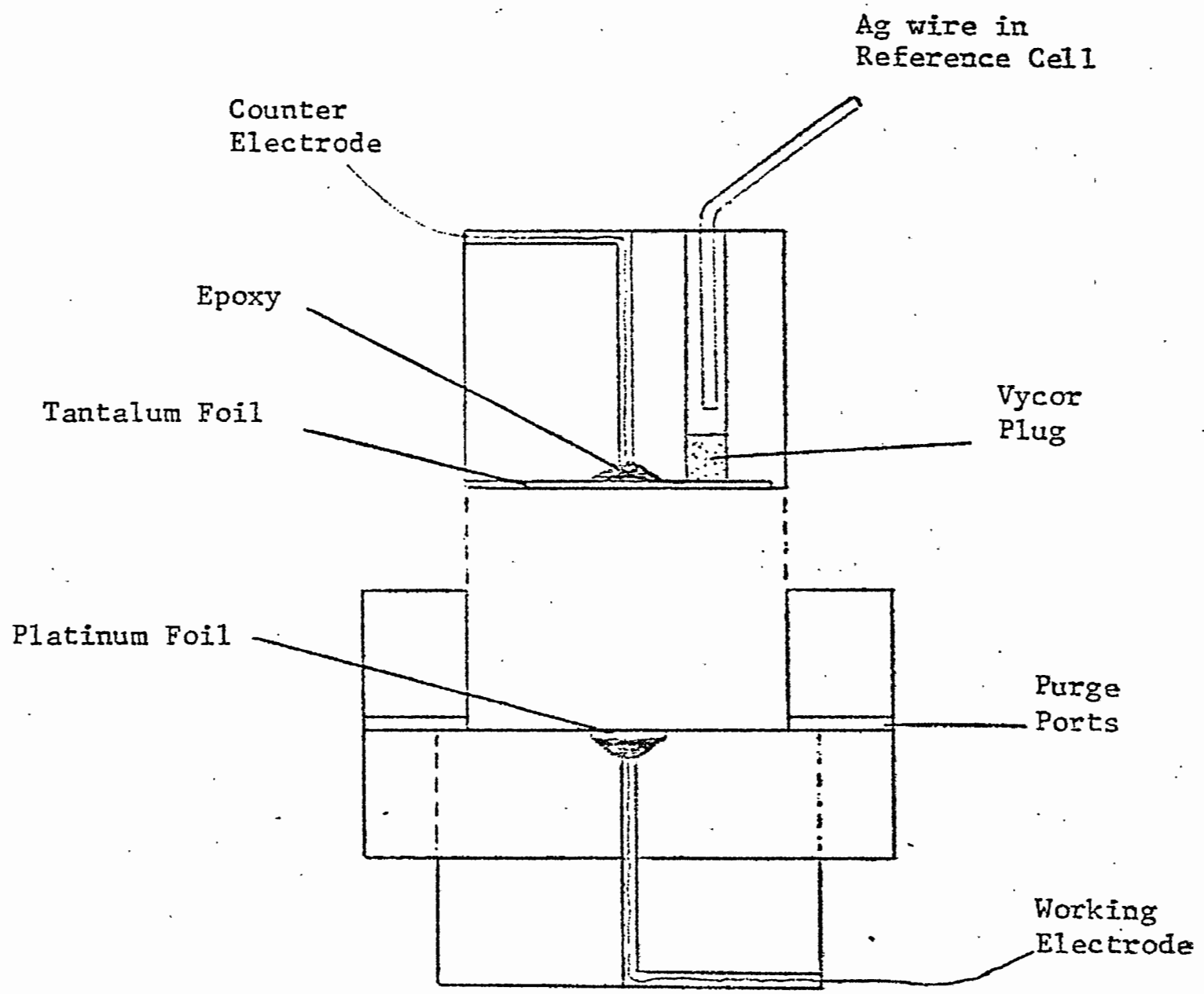

Figure 1. Cutaway diagram of electrochemical cell. 


\section{PROCEDURE}

The procedure is fairly straightforward and will be presented fully here.

One centimeter round discs of ion-exchange paper were conveniently cut with a cork borer and placed in the filtering apparatus shown in Figure 2. The ferrous and/or ferric samples were adjusted to $\mathrm{pH} 2$ with $\mathrm{HCl}$, if necessary, and a sufficient volume was drawn through a previously water soaked disc at a constant rate. It is necessary to swell the resin beads or exchange capacity will be severely diminished. Care was taken not to exceed about thirty percent capacity as collection efficiencies could suffer (20). The filtration was halted while there was still a few milliliters of solution above the disc in an effort to prevent large quantities of air from passing through and possibly oxidizing the ferrous. iron.

The disc was then removed with tweezers, the excess solution removed by shaking or blotting, and quickly placed into the electrochemical cell. Ten microliters of acetate buffer were added and a baseline current was obtained by scanning both directions from the "zero current potential" (described below). Then, ten microliters of a saturated EDTA solution and two microliters of $0.1 \mathrm{M}$ malonic acid were added. The instrument then located the zero current potential, or the voltage necessary to just counter the net redox potential of all the substances in the cell, so that no charge flowed in either direction. From this point a scan was made in the positive direction (anodically) to measure the current due to the oxidation of ferrous to ferric iron. Then, by returning to the :zero current potential for one minute to reconvert the newly 

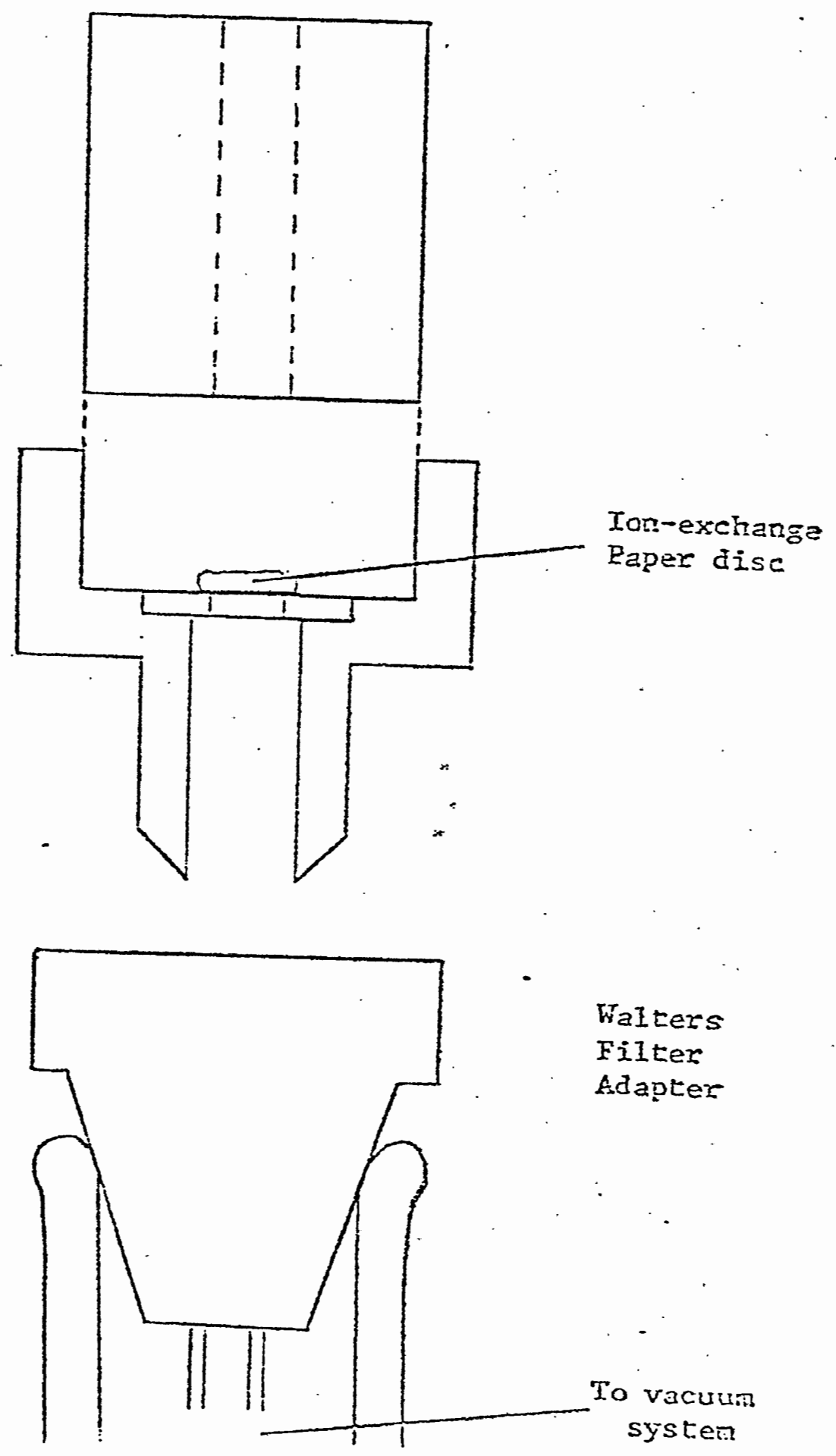

Walters

Filter

Adapter

To vacuun systen

Figure 2. Cutaway diagram of filtering apparatus. 
formed $\mathrm{Fe}$ (III) back to $\mathrm{Fe}(\mathrm{II})$ to reestablish the original proportion of the oxidation states, a cathodic scan was made to measure the current of the reduction of ferric to ferrous iron. Since the current is proportional to concentration, it was a relatively simple matter to construct a calibration curve of different iron concentrations.

Natural Water Samples

The procedure remained the same except for the solubilization of iron. Two identical water samples were collected and one was adjusted to $\mathrm{pH} 1.0$ with $\mathrm{HCl}$ at the time of collection. The unacidified sample was filtered through a $0.45 \mu$ filter and the filtrate was then acidified to $\mathrm{pH} 1.0$ and evaporated at $90-100^{\circ} \mathrm{C}$ for one hour, then cooled and diluted to volume. A suitable aliquot, adjusted to $\mathrm{pH} 2.0$, was then filtered through a $\$ 42$ Whatman filter placed on top of an ion-exchange disc. This was classified as the 'soluble organic' fraction.

The acidified sample was solubilized and filtered, in the same manner as above, except without pre-filtering with the $0.45 \mu$ filter. This was classified as the 'total HCl extractable' fraction. The difference between the two fractions would be the 'suspended organic' fraction.

The $\$ 42$ filter paper remaining from the 'total HCl extractable' fraction was dissolved in $2 \mathrm{ml}$ of hot concentrated nitric acid in a platinum crucible, cooled and diluted with distilled water and analyzed by atomic absorption. This was classified as the 'organic solid' fraction. The crystalline deritus remaining in the crucible was fused with anhydrous sodium carbonate in a mufíle furnace at $1000^{\circ} \mathrm{C}$ for twenty minutes. This was cooled, taken up with two milliliters of distilled water, three drops concentrated $\mathrm{HCl}$ and one milliliter of concentrated per- 
chloric acid to dehydrate the silica. The solution was evaporated to dryness, cooled and taken up with three drops of concentrated sulfuric acid and one milliliter of hydrofluoric acid and again evaporated to dryness. This was diluted to volume and analyzed by atomic absorption. This fraction was referred to as the 'insoluble crystalline' fraction. Reagent blanks were carried through all phases of the solubilization steps. 


\section{Effect of $\mathrm{pH}$}

The ion exchange capacity of a resin can be affected by the pH of the sample solution, especially where weak acid or base resins are involved. In general, when the $\mathrm{pH}$ of a solution falls below the pK of cation exchange groups or rises above the $\mathrm{pK}$ of anion exchange groups, the efficiency of collection drops off significantly because the exchange groups become largely unionized. In a strong acid resin, such as the one used in this study, the effect of low $\mathrm{pH}$ should be minimal.

The dependence of $\mathrm{pH}$ was determined by a filtration procedure applied to a duplicate series of ten milliliter solutions containing six micrograms each of $\mathrm{Fe}(\mathrm{II})$ and $\mathrm{Fe}$ (III) at various $\mathrm{pH}$ levels. The flow rate was held at $9.2 \mathrm{ml} / \mathrm{min}$ and the quantity of each ion collected was quickly determined by analyzing the solutions before and after filtration by atomic absorption spectrophotometry. The results are given in Table I.

\section{TABLE I}

EFFECT OF PH ON EXTRACTION EFFICIENCY

$\begin{array}{ccc}\underline{\mathrm{pH}} & \begin{array}{l}\% \mathrm{Fe} \text { (III) } \\ \text { Extracted }\end{array} & \begin{array}{l}\text { \% Fe(II) } \\ \text { Extracted }\end{array} \\ 2.0 & 70 \pm 1 & 65 \pm 1 \\ 2.5 & 74 \pm 1 & 68 \pm 2 \\ 2.0 & 81 \pm 1 & 74 \pm 1 \\ 1.5 & 74 \pm 2 & 65 \pm 1 \\ 1.0 & 68 \pm 2 & 52 \pm 2\end{array}$


A $\mathrm{pH}$ of 2.0 was deemed most efficient for the collection of iron. The efficiency of collection decreases at low $\mathrm{pH}$ probably due to competition at the exchange site between iron and hydrogen ions. The collection decreases at higher $\mathrm{pH}^{\prime}$ 's presumably because hydroxy complexes are being formed which decrease the positive charge on the ion and lower the distribution coefficient.

\section{Equilibrium Distribution Coefficient}

A complexing agent needed to be found that had a higher stability constant for iron than either ion did for the resin, so an experiment was designed to estimate the equilibrium distribution coefficient, $K_{d}$, for each ion between the resin and the solution. This coefficient is given to be (21)

$$
\mathrm{K}_{\mathrm{d}}=\frac{\mathrm{b}_{\mathrm{r}}}{\mathrm{b}_{\mathrm{w}}} \frac{\mathrm{w}}{\mathrm{g}}
$$

where $b_{r}$ is the quantity of ion $b$ collected by the resin, $b_{w}$ is the amount of ion remaining in solution, $w$ is the volume of the solution usually expressed in weight and $g$ is the weight of the resin.

A disc of ion-exchange paper was placed into ten milliliters of each iron solution at $\mathrm{pH}$ 2.0. After swirling each solution for an hour to achieve equilibrium, the remaining iron in solution was measured by atomic absorption. The distribution coefficients were determined to be

$$
\begin{array}{lll}
\mathrm{Fe} \text { (II) } & \mathrm{K}_{\mathrm{d}}=500 & \log \mathrm{K}_{\mathrm{d}}=2.7 \\
\mathrm{Fe} \text { (III) } & \mathrm{k}_{\mathrm{d}}=12600 & \log \mathrm{K}_{\mathrm{d}}=4.1
\end{array}
$$

Several strong complexing agents were evaluated for their ability to effectively remove the iron from the resin and bring it into solution: sodium. oxalate; sodium cyanide, EDTA, potassium cyanate, malonic acid, 
sodium citrate, sodium tartrate, salicylic acid, potassium thiocyanate and pyrocatechol. Of these, the system that would bind both iron forms sufficiently well, have the lowest order of toxicity and provide the greatest coulombic current was EDTA. The effective formation constants for the iron-EDTA complexes (22)

$\begin{array}{ll}\mathrm{Fe} \text { (II) } & \log \mathrm{K}_{\mathrm{f}}=8.9 \\ \mathrm{Fe}(\mathrm{III}) & \log \mathrm{K}_{\mathrm{f}}=19.6\end{array}$

are greater than for any of the other compounds indicating that this is the most stable complex formed and would be expected to be the best choice.

It is interesting to note that while malonic acid alone gives a very poorly defined redox potential vs. current curve, a combination of malonic acid and EDTA (optimally a 1:50 molar ratio) gives a current peak more than double that of EDTA alone. No explanation of this phenomena is attempted here other than a mixed complex may be formed which somehow promotes elution of the iron ions.

\section{Calculation of Optimum Flow Rate}

In an attempt to predict the relative exchange efficiencies of ferrous and ferric iron to show that the method would indeed be feasible, a calculation of the total plate height in the resin paper was made according to Helfferich (23).

$$
H=1.64 r+\frac{0.14\left(r^{2}\right) F K}{\bar{D}\left(a^{2}\right)}+\frac{0.266 r^{2} F K}{D(1+70 r F) a^{2}}+\frac{D \alpha \sqrt{2}}{F}
$$


$H=$ effective height of a theoretical plate

$r=$ radius of swollen resin particle

$\mathrm{f}=\mathrm{flow}$ rate

$\bar{D}=$ diffusion coefficient of ion in resin

$\mathrm{D}=$ diffusion coefficient of ion in solution

$\alpha=$ fractional void volume of bed

$\mathrm{K}=$ distribution coefficient
(EHTP)

$(0.0018 \mathrm{~cm})$

(variable)

$\left(\sim 10^{-6} \mathrm{~cm} \mathrm{sec}{ }^{-1}\right)$

( $10^{-5} \mathrm{~cm} \mathrm{sec}^{-1}$ )

$(0.7)$

$(\mathrm{Fe}(I I)=500)$

$(\mathrm{Fe}(\mathrm{III})=12600)$

(depends on ion used)

$a=k+\alpha \simeq K$

The first term is due to finite particle size, the second to slow particle diffusion, the third to slow film diffusion and the fourth to longitudinal diffusion. By plotting various flow rates versus theoretical plate height, the graph in Figure 3 was obtained. The low points on the graphs indicate the smallest plate height, or most efficient flow rate. It is also seen that ferrous iron, with the smaller distribution coefficient has the faster respective band movement and consequently the larger plate height. Now we can calculate the number of theoretical plates in the resin disc under optimal flow conditions and predict the relative exchange efficiencies. They are shown in Table II.

As can be seen from the table there should not be any detrimental effect of increasing the flow rate on the plate height and consequently the efficiency of the metal uptake. Predicting optimal performance of resin columns based on.linear approximations of the rate laws of diffusion is admittedly only a rough approximation, especially when the system is seldom, if ever, in an equilibrium condition. However, with a few calculations, a great deal of time may be saved in designing a system with a high probability of success. 


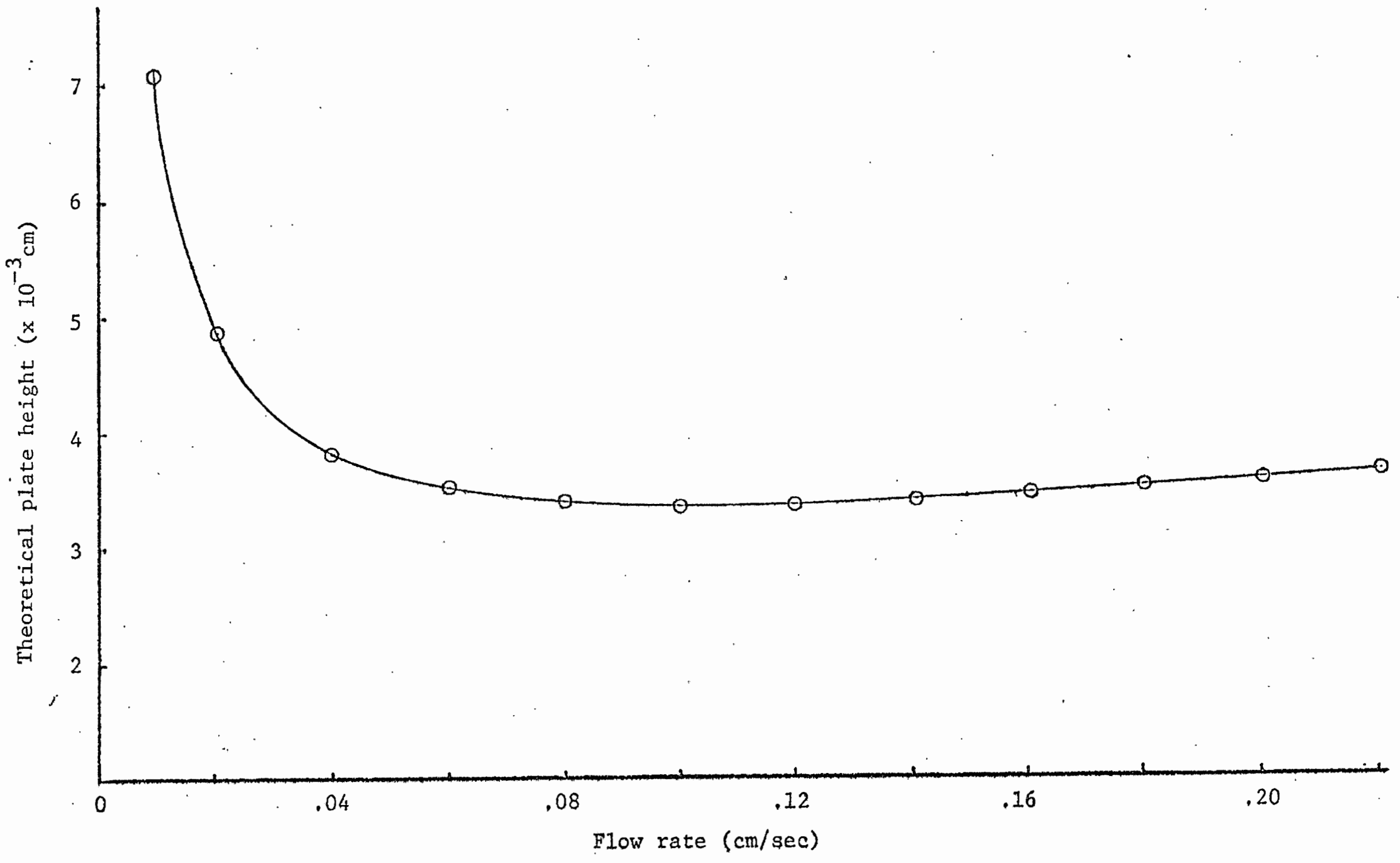

Eigure 3. Calculation of optimum flow rate vs plate height for Fe(II). 
TABLE II

OPTIMUM AND EXPERIMENTAL ION EXCHANGE PARAMETERS

Condition

Optimum Flow Rate (cm/sec)

Optimum Flow Rate $\left(\mathrm{cm}^{3} / \mathrm{min}\right)$.

Equivalent height of plate (Optimum)

Number of plates (Optimum)

Experimental Flow Rate (cm/ sec)

Experimental Flow Rate $\left(\mathrm{cm}^{3} / \mathrm{min}\right)$

Equivalent height of plate (Exp)

Number of plates (Exp)

Relative Exchange Efficiency (\%)
$\underline{\mathrm{Fe}}(\mathrm{II})$

0.10

4.7

$3.16 \times 10^{-3} \mathrm{~cm}$

12

0.20

9.2

$3.21 \times 10^{-3} \mathrm{~cm}$

12

92
$\underline{F e(I I I)}$

0.48

23

Figure 4 depicts an actual scan of the Fe-EDTA complex on the filter paper in the cell. The EDTA puIls the iron from the resin and brings it into solution and in contact with the electrodes. The complexing of EDTA was determined to be essentially instantaneous; at any rate, to occur within a few seconds before the cell could be connected to the potentiostat. The coulombic current, and hence the complex, remained stable over the course of several hours.

Figure 5 shows the calibration curves of the simultaneous analysis of a series of standard $\mathrm{Fe}$ (II)-Fe(III) mixtures. The maximum standard deviation for a triplicate analysis of a single standard did not exceed eight percent. 


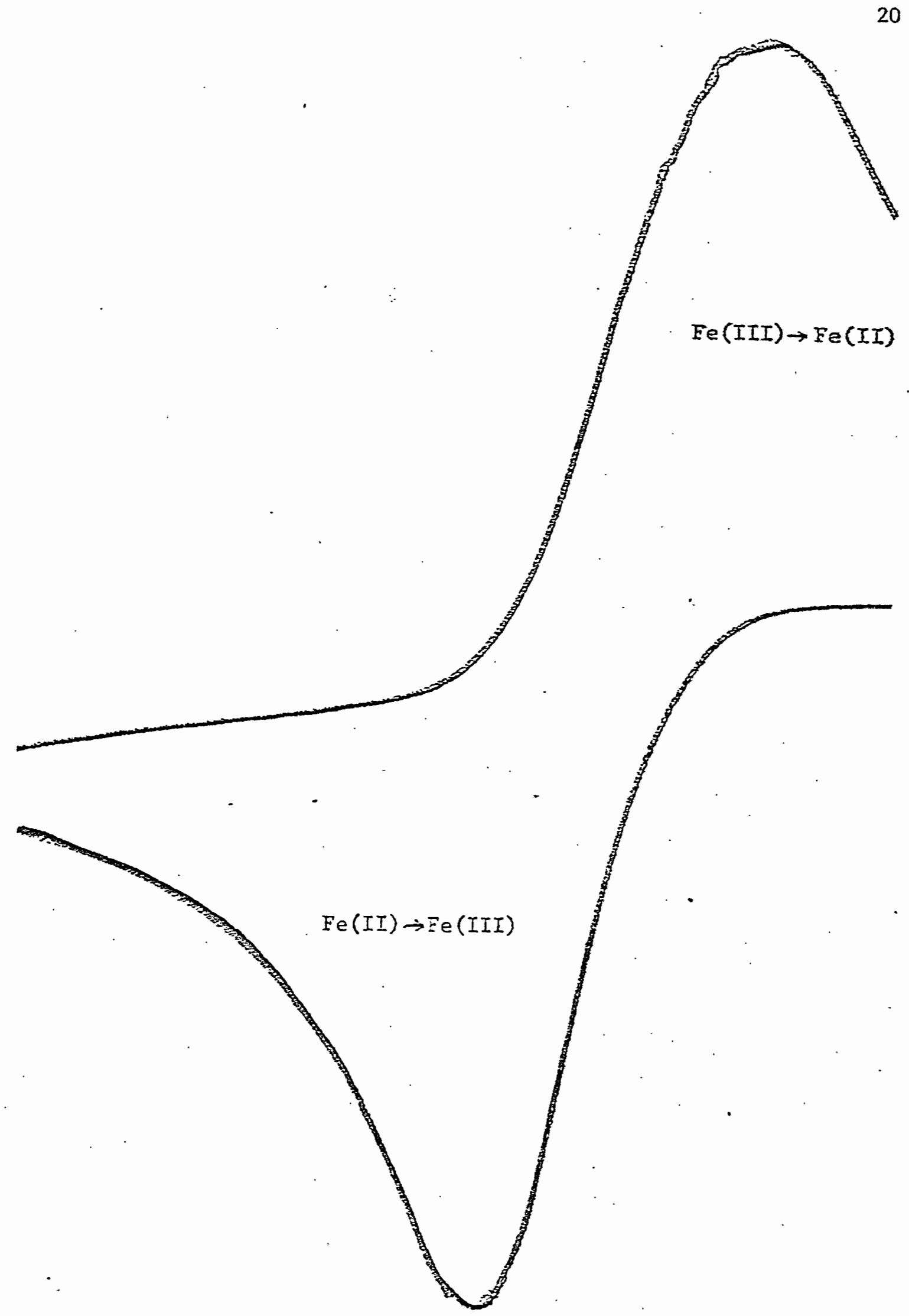

Figure 4. A cyclic scan showing the redox current curvie for Fe-EDTA. 


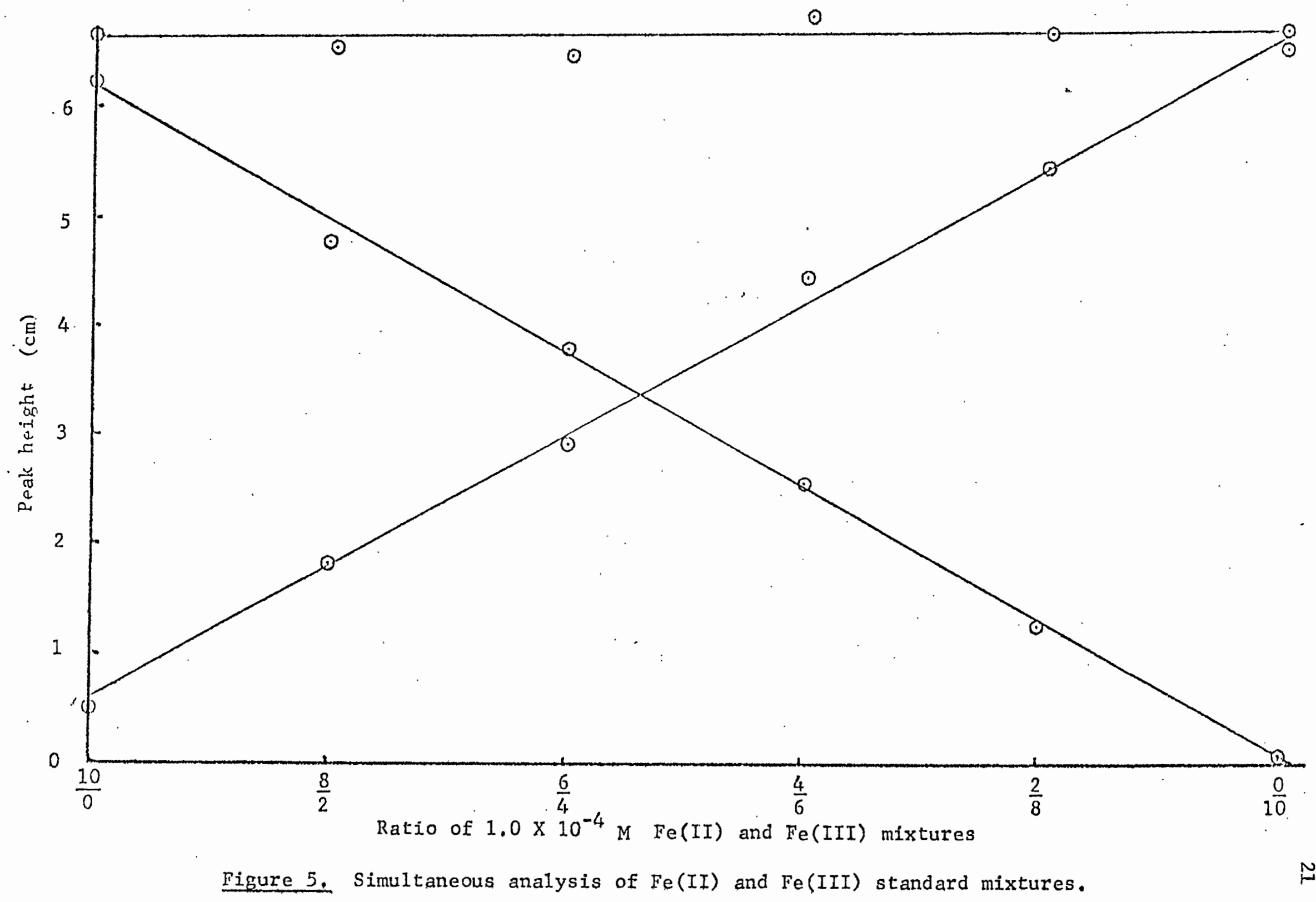




\section{Effect of Filtration Rate}

The vacuum apparatus was restricted to a minimum flow rate of 9.2 $\mathrm{ml} / \mathrm{min}$ (the solution does not flow through the resin disc by gravity alone) and an experiment was completed to determine if faster flow rates could be used without creating collection problems. Duplicate ten milliliter solutions of both ions, adjusted to $\mathrm{pH} 2.0$, were run at different flow rates and the results are shown in Table III. It is evident that the slowest flow rate is conducive to the highest precision.

\section{TABLE III}

EFFECT OF FILTRATION RATE ON COLLECTION EFFICIENCY

Ion

$\mathrm{Fe}(I I)$

$\mathrm{Fe}(\mathrm{II})$

$\mathrm{Fe}(\mathrm{II})$

$\mathrm{Fe}$ (III)

$\mathrm{Fe}$ (III)

$\mathrm{Fe}$ (III)

\section{Filtering Rate} $(\mathrm{mI} / \mathrm{min})$

24

15

9.2

24

15

9.2
Average \% Collected

$68 \pm 3$

$71 \pm 2$

$74 \pm 1$

$65 \pm 3$

$68 \pm 4$

$81 \pm 1$

\section{Quantitative Exchange}

The filtration procedure was applied to both ions in an experiment to determine the number of filtrations through one disc needed to obtain quantitative removal. The quantity of ion collected will depend on the amount of ion in solution, the percent loading of the exchange sites, and the affinity of the ion for the resin $\left(\mathrm{K}_{\mathrm{d}}\right)$, which is determined by a number of other factors. It is noticed in Table IV that at least five filtrations of the same sample are needed to attain nearly complete ex- 
traction of the ion. This seeming inefficiency is probably due to the very short length of the resin 'column' and, consequently the lack of a sufficient number of theoretical plates.

TABLE IV

AVERAGE \% IRON COLLECTED IN NULTIPLE FILTRATIONS

$\begin{array}{ccccc}\text { Ion } & & \frac{\text { Number of Filtrations }}{3} & \underline{5} & \underline{7} \\ \mathrm{Fe}(\mathrm{II}) & 74 \pm 1 & 93 \pm 1 & 98 \pm 0 & >99 \\ \mathrm{Fe}(\mathrm{III}) & 81 \pm 1 & 95 \pm 1 & 99 \pm 1 & >99\end{array}$

\section{Buffer Choice}

The ionic strength of natural waters is almost always too low to permit the use of analytical techniques requiring an electrical measurement so an acetate buffer of $\mathrm{pH} 5.5$ was used to control the ionic strength of the system because of the relatively low complexing power of the acetate ion (24). It was subsequently learned that another research group (25) had chosen an acetate medium for its studies of metal complexation.

Oxidation of Fe(II)

Stumm and Lee (26) examined critically the oxidation of Fe(II) by. oxygen and discovered that the process is very $\mathrm{pH}$ dependent. However, below $\mathrm{pH} 4$ the oxidation process is not characterized by the same kinetic relationships and it is independent of $\mathrm{pH}$. The rate then, had to be determined experimentally for the conditions that vould exist in the solubilization procedure. A solution of ferrous ion was adjusted to $\mathrm{pH} 2.0$ and heated to $90^{\circ} \mathrm{C}$. At intervals of one hour, a sample of the solution was checked for loss of ferrous iron by the ortho-phenanthroline method (27). 


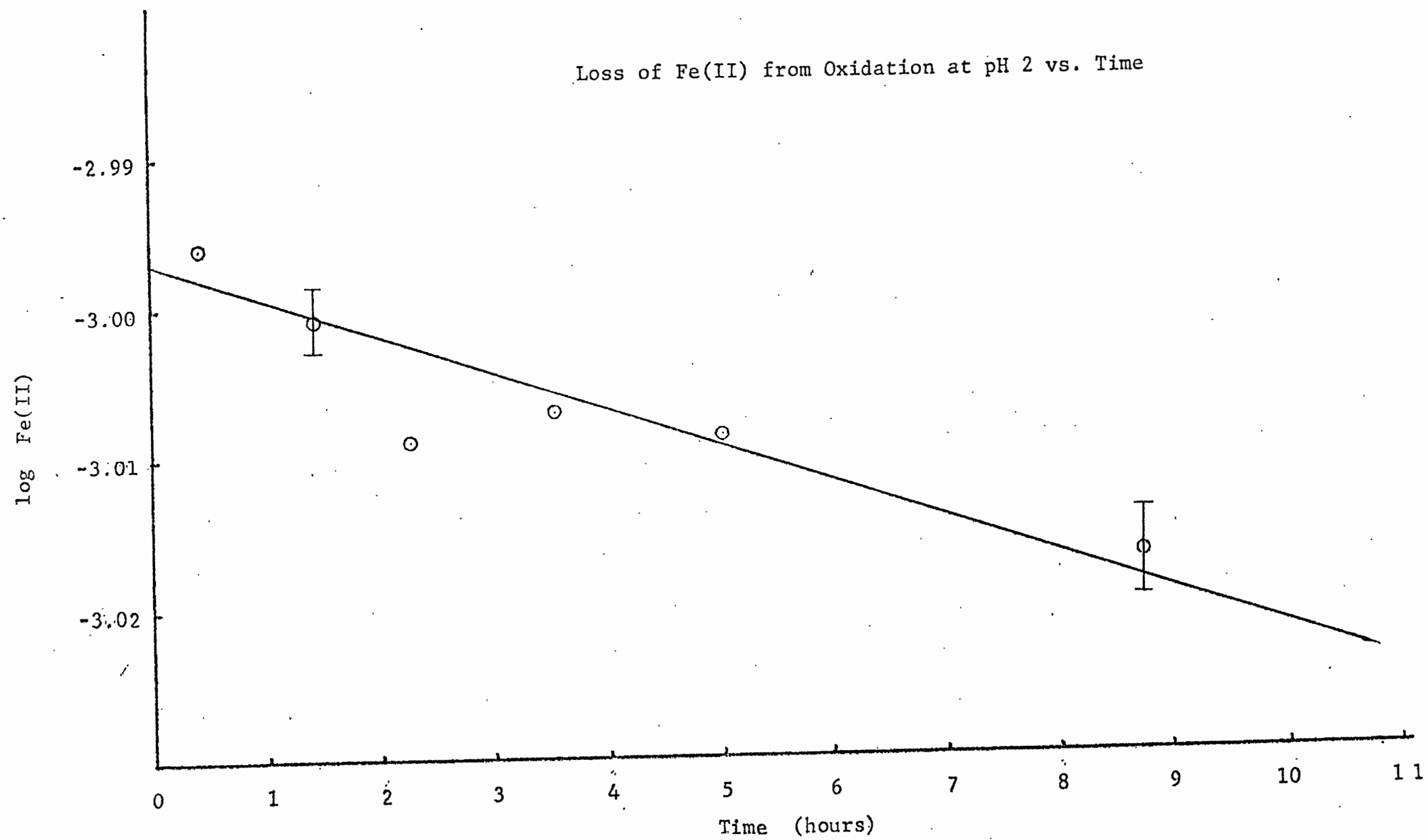

Figure 6. Loss of $\mathrm{Fe}(\mathrm{II})$ from oxidation at $90^{\circ} \mathrm{C}$ and $\mathrm{pH} 2.0$ vs time. 
The results of the experiment are in Figure 6 . The rate was approximately $5 \%$ oxidation in ten hours which is negligible since the solubilization takes only two hours to complete.

Natural Water Results

The results of five river water samples are depicted in Table $V$. The total iron, analyzed in part by LSV, is compared to the results obtained from atomic absorption and the agreement is quite reasonable. The standard deviation in the AA values and the LSV values is approximately $10 \%$

The 'soluble organic' fraction is expected to contain small amounts of inorganic iron compounds, organically complexed iron, colloidal iron and particulates which pass through the $0.45 \mu$ filter. This filter size only operationally defines soluble iron as it has been shown that the fraction of 'soluble' iron often decreases in a Iinear fashion with decreasing pore size (28). The 'suspended organic' fraction probably contains mostly adsorbed iron on clay and other suspended particulate, and iron bound in animal or vegetable matter. The remaining 'organic solid' fraction contains very little, if any, organic iron which is not HCI soluble. The origin of this iron remains questionable, but its presence in this form is probably insignificant in the total iron distribution. The 'insoluble crystalline' material is undoubtedly composed of siliceous minerals possibly incorporating iron into the silicate structure by exchange with aluminum ions (29).

It can be seen that the total HCl extractable fraction only amounts to about fifty percent of the total iron. This is the fraction that would be redox active and available for plant and animal metabo1ism. 'The iron bound in the insoluble crystalline fraction is essen- 
TABLE V

FRACTIONAL ANALYSIS OF IRON IN FIVE RIVER WATER SAMPLES

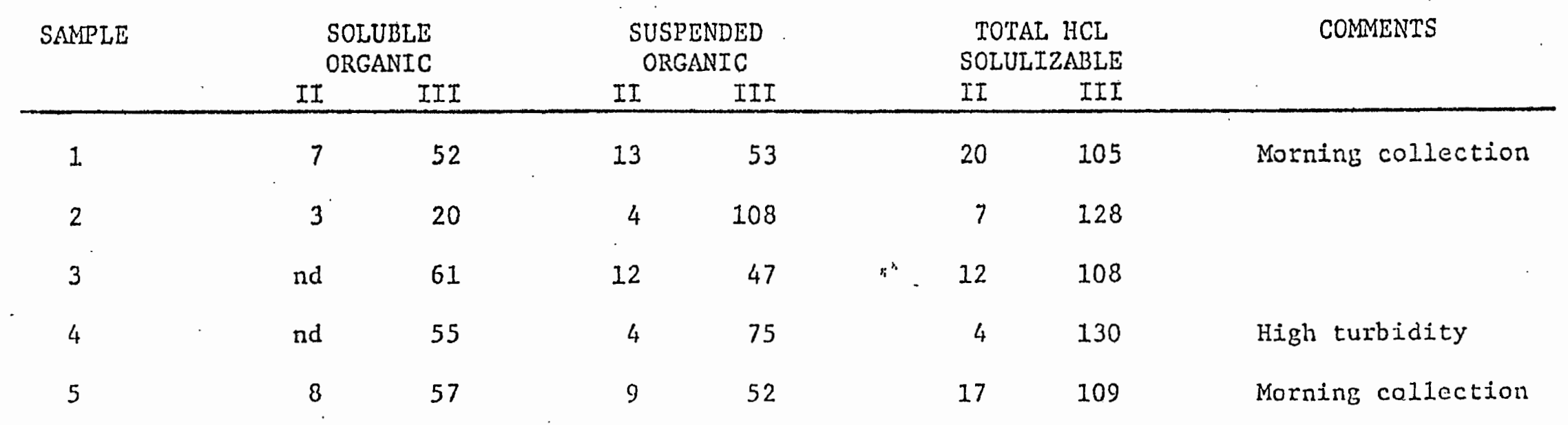

\begin{tabular}{|c|c|c|c|c|c|}
\hline SAMPLE & $\begin{array}{l}\text { TOTAL HCL } \\
\text { SOLULIZABLE }\end{array}$ & ORGANIC SOLID & $\begin{array}{l}\text { INSOLUBLE } \\
\text { CRYSTALLINE }\end{array}$ & $\begin{array}{c}\text { TOTAL } \\
\text { LSV }\end{array}$ & $\begin{array}{c}\text { TOTAL } \\
\text { AA }\end{array}$ \\
\hline 1 & 125 & -- & $-\infty$ & $-\infty$ & 230 \\
\hline 2 & 135 & $-\cdots$ & $-m$ & -- & 230 \\
\hline $3^{\prime}$ & & & & & \\
\hline 3 & 120 & 3 & 120 & 240 & 220 \\
\hline 5 & 126 & 4 & 140 & 270 & 250 \\
\hline
\end{tabular}

Al1 cisncentrations are $\ln \mu g / 1$. nd $=$ not detected. 
tially removed from any further solution reactions. The early morning collections of samples one and five show a slight increase of $\mathrm{Fe}$ (II) in the total $\mathrm{HCl}$ extractable fraction which may occur during the night when the dissolved oxygen concentration drops and the absence of light prevents photochemical oxidation reactions. It may be possible, then, that a diurnal curve exists for $F e(I I)$ similar to that of dissolved oxygen. A slight effect on the ratios of iron species was seen in sample four when it was noted that the sample was more turbid than usual. The significance of this effect was unknown.

The results of this work do not necessarily negate any of the four assumptions made in the introduction, but it does not absolutely confirm them either. The presence of colloidal iron, $\mathrm{Fe}_{n}(\mathrm{OH})_{3 n}$, was quite possibly interfering in the determination of the organic and particulate fractions because the $0.45 \mu \mathrm{m}$ filter can not filter the tiny colloidal fraction (diameters of $<0.1 \mu$ ). Consequently, there appears to be a great deal of $\mathrm{Fe}$ (III) in the system not accounted for by the slight amount of $\mathrm{Fe}(\mathrm{II})$ being oxidized during the procedure. 


\section{RECOMMENDATIONS}

of particular importance in future studies concerning trace metal speciation should be the further attempts to delineate the inorganic species, with the development of new and better ion-selective electrodes, and the colloidal fractions. Information concerning the environmental fate of metal pollutants is especially in need of updating and revision. Results from recent studies indicate a substantial solubilization effect of some detergent additives, however, very little is known concerning the occurence of anthropogenic sources of potential metal complexing agents.

The mechanisms by which metals are complexed to organics and the strength of which they are bound could have a significant effect on the removal of the toxic effects of metals, but this information remains mostly unknown to date. A complete understanding of the possible roles of metal-organic interactions must await further investigations of our environment. 
1. Stiff, M.J., Water Resources 5:585-599 (1971).

2. Barber, R.T., J. Exp. Mar..Biol. Ecol. 3:191-199 (1969).

3. Schroeder, H.A., J.Chron. Dis. 19:85-106 (1966).

4. Water Quality Crieteria Data Book, Volume II. EPA Publication (1971).

5. Schroeder, H.A. and Mitchener, M., J. of Nutr. 101:1531 (1971).

6. Water Quality Criteria Data Book, Volume II. EPA Publication (1971).

7. Cilley, W.A., Environ. Letters, 2:121-129 (1971).

8. Ey1, T.B., New England Journal of Medicine, 284:706 (1971).

9. Hanck, K.W. and Dillard, J.W., "Determination of the Complexing Capacity of Natural Water", NTIS Bulletin PB-227, 874 (1973).

10. Leland, A.V., Shulela, S.S. and Shimp, N.R., "Factors Affecting Distribution of Lead and Other Trace Elements in Sediments of Southern Lake Michigan". In Trace Metals and Metal-Organic Interactions in Natural Waters; Phillip Singer, Ed., p. 89 (1973).

11. Gibbs, R.J., Science 180:73 (1973).

12. Schnitzer, M. and Skinner, S.I.M., Soil Sci., 102:361-365 (1967).

13. Theis, T.L. and Singer, P.C., "The Stabilization of Ferrous Iron by Organic Compounds in Natural Waters", In Trace Metals and MetalOrganic Interactions in Natural Waters". Phillip Singer, Ed., p. 303 (1973).

14. Reshid, M.A., Soil Sci., III:298-305 (1971).

15. McKee, J.E., Ed., "Water Quality Criteria", The Resources Ag. of Cal. State Water Quality Control Board No. 3-A (1963).

16. Brown, E., Skougstad, M.W. and Fishman, M.J., "Methods for Collection and Analysis of Water Samples for Dissolved Minerals and Gases", USGS Bulletin No. 2401-1015 (1974). 
17. Neilands, J.B., "Chemistry of Iron in Biological Systems", In Metal Ions in Biological Systems, Dhar, Ed. (1974).

18. Dinsel, D.L. and Sweet, T.R., Anal. Chem., 35:2077-2081 (1963).

19. Booman, G.L. and Holbrook, W.B., Anal. Chem. 37:795-802 (1965).

20. Roe, D.K., Personal communication.

21. CampbelI, W.J., Spano, E.F. and Green, T.E., "Micro and Trace Analysis Using Ion Exchange Resin-Loaded Papers and $X$-Ray Spectrography", In Symposium on Trace Characterization Chemical and Physical, NBS Publication (1966).

22. Day, R.A. and Underwood, A.L., Quantitative Analysis, PrenticeHall, New Jersey (1967).

23. Helfferich, F., Ion Exchange, McGraw-Hill, New York, N.Y. (1962).

24. Meitos, L. Handbook of Analytical Chemistry, McGraw-Hill, New York, N.Y. (1963).

25. Hanck, K.W. and Dillard; J.W., "Determination of the Complexing Capacity of Natural Water" NITS Bulletin PB-227, 874 (1973).

26. Stumm, W. and Lee, G.F., Ind. Eng. Chem., 53:143 (1961).

27. Brown, E., Skougstad, M.W. and Fishman, M.J., "Methods for Collection and Analysis of. Water Samples for Dissolved Minerals and Gases", USGS Bulletin No. 2401-1015 (1974).

28. Andelman, J.B., "Incidence, Variability and Controlling Factors for Trace Elements in Natural, Fresh Waters", Trace Metals and Metal Organic Interactions in Natural Waters, Phillip Singer, Ed., Ann Arbor Science (1973).

29. Perdue, E.M., Personal communication. 